\title{
A study of tensile and bending properties of 3D-printed biocompatible materials used in dental appliances
}

\author{
Marcos García Reyes ${ }^{1}$, Alex Bataller Torras ${ }^{1}$, Juan A. Cabrera Carrillo ${ }^{1}$, Juan M. Velasco García ${ }^{1}$, and \\ Juan J. Castillo Aguilar ${ }^{1, *}$ (D) \\ ${ }^{1}$ Department of Mechanical Engineering, University of Málaga, Málaga, Spain
}

Received: 30 October 2021

Accepted: 6 December 2021

Published online:

3 January 2022

(C) The Author(s) 2021

\begin{abstract}
In the last years, a large number of new biocompatible materials for 3D printers have emerged. Due to their recent appearance and rapid growth, there is little information about their mechanical properties. The design and manufacturing of oral appliances made with 3D printing technologies require knowledge of the mechanical properties of the biocompatible material used to achieve optimal performance for each application. This paper focuses on analysing the mechanical behaviour of a wide range of biocompatible materials using different additive manufacturing technologies. To this end, tensile and bending tests on different types of recent biocompatible materials used with 3D printers were conducted to evaluate the influence of the material, 3D printing technology, and printing orientation on the fragile/ductile behaviour of the manufactured devices. A test bench was used to perform tensile tests according to ASTM D638 and bending tests according to ISO 178. The specimens were manufactured with nine different materials and five manufacturing technologies. Furthermore, specimens were created with different printing technologies, biocompatible materials, and printing orientations. The maximum allowable stress, rupture stress, flexural modulus, and deformation in each of the tested specimens were recorded. Results suggest that specimens manufactured with Stereolithography (SLA) and milling (polymethyl methacrylate PMMA) achieved high maximum allowable and rupture stress values. It was also observed that Polyjet printing and Selective Laser Sintering technologies led to load-displacement curves with low maximum stress and high deformation values. Specimens manufactured with Digital Light Processing technology showed intermediate and homogeneous performance. Finally, it was observed that the printing direction significantly influences the mechanical properties of the manufactured specimens in some cases.
\end{abstract}

Handling Editor: Annela M. Seddon.

Address correspondence to E-mail: juancas@uma.es 


\section{Introduction}

The dental sector is in continuous evolution towards the use of the latest technological advances [1-5]. Nowadays computer-aided design and manufacturing (CAD/CAM), which includes additive manufacturing (AM) techniques, are often used for the digital workflow in dentistry. Such technologies are used for the design of dental arches and appliances through data recording with intraoral scanners (IOS) $[6,7]$. Furthermore, IOS was used in $[8,9]$ to acquire the dental images, which were designed to realize prosthetic dentistry. CAD/CAM technologies have also been proposed for the evaluation and planning of surgical interventions and for the design of dental devices [10-12]. Some of the most common examples are the design of teeth $[13,14]$ and orthopaedic devices [15] and the planning of dental movements with a high degree of accuracy [16, 17]. Schweiger et al. showed to what extent 3D printing can be used in dental laboratories and dental practices at present [18]. Similarly, 3D printing and AM can be applied to a wide range of medical applications [19]. This way, Abid Haleem et al. performed a review of the applications of 3D printing in bone tissue engineering [20], Genoa et al. studied the main factors that are critical for bioprinting in bone tissue engineering [21] and Daniela et al. proposed a novel synchronized dual bioprinting approach for mechanically and biologically improved substitutes for cartilage tissue engineering [22]. Finally, different additive manufacturing techniques applied in the design, diagnosis and planning of a locked intramedullary nail used in the diaphyseal femoral fractures were studied by Fernandes et al. [23].

The mechanical properties of biocompatible materials have to be taken into account to properly design dental devices with 3D printing technology. An inappropriate choice of material can lead to breakage or high deformation, causing poor performance of the manufactured device. In addition, the printing direction of the device has to be carefully selected due to its influence on the mechanical properties of the manufactured part.

CAD/CAM technologies have been boosted in recent years by the emergence of biocompatible materials for 3D printing in the dental sector [24]. In recent times, 3D printing has acquired fundamental importance in the design of devices and dental pieces. New biocompatible materials are appearing to be used with this technology and the accuracy and speed of the manufacturing process are continuously increasing. Seven AM categories have been identified according to the American Society for Testing and Materials (ASTM) Committee F42 on AM technologies. These are the following: stereolithography (SLA), material jetting (MJ), material extrusion or fused deposition modelling (FDM), binder jetting, powder bed fusion, sheet lamination, and direct energy deposition. The following printing technologies have been used in this paper: Polyjet, Selective Laser Sintering (SLS), Digital Light Processing (DLP), and Stereolithography (SLA) [25, 26]. The most commonly used AM technologies in dentistry nowadays are SLA and MJ due to the appearance of novel photopolymer and biocompatible materials and their high resolution [27-29].

The use of 3D printing is widely extended in the manufacturing of models for the production of invisible teeth aligners. In recent years, great advances have been made in biocompatible materials that allow the manufacturing of complete functional devices such as mandibular advancement devices, mouth guards, surgical splints, hearing aids, and cutting guides [30]. In this sense, the ASTM has already set technical standards for a wide range of applications, designs, materials and processes, terminology, and test methods related to additive manufacturing. In this paper, tests have been conducted according to general testing ASTM standards for traction and bending tests. According to these standards, the anisotropic behaviour has to be considered to have a better knowledge of the mechanical characteristics of a material. This anisotropy is especially important in 3D printing techniques, where parts are created through the superposition of layers of material. Therefore, different properties are expected in each direction.

Materials used in thermoformed invisible splints have been thoroughly studied. They are well-known for their mechanical behaviour over time [31-34]. However, this is not the case with new biocompatible materials for $3 \mathrm{D}$ printing. This paper aims to analyse the behaviour of a wide range of biocompatible materials used in different additive manufacturing technologies. To this end, their mechanical properties for different layer orientations have been determined using standardised tensile and bending tests. The analysis of the results can help producers select the 
most suitable material, printing system, and printing orientation according to the desired characteristics of the device to be manufactured.

The study of the change of the properties of the manufactured parts over time depending on the biocompatible materials utilized and the environmental conditions where they are used is out of the scope of this paper. It is worth mentioning that there are many studies referring to the different existing technologies, their precision in terms of layer thickness, and the influence of post-printing treatments [35-37]. Several works have also studied the effect of print orientation in the printing process on the mechanical properties of manufactured specimens. [38-40]. However, to the best of our knowledge, there is no information about the mechanical behaviour of materials used for the development of dental devices in which different additive manufacturing technologies, biocompatible materials, and layer orientation have been taken into account. These data are of great interest to researchers to select the most appropriate material and printing method to manufacture dental devices.

\section{Materials and methods}

In this paper, the main biocompatible materials existing on the market for $3 \mathrm{D}$ printing that can be used for dental applications have been selected. Thus, the materials tested in this work were one for milling technology (PMMA) and eight for different 3D printing technologies: one for Polyjet, two for Selective Laser Sintering (SLS), three for Digital Light Processing (DLP), and two for laser-based Stereolithography (SLA). These materials are certified biocompatible in compliance with ISO 10993-1:2010 [41]. This way, selected materials meet the requirements for dental applications in terms of cytotoxicity, sensitivity, and irritation according to this international standard. In the case of the milling technology, the initial workpiece was a cylinder with a diameter of $12 \mathrm{~cm}$ and a thickness of $40 \mathrm{~mm}$. These dimensions made it impossible to manufacture a specimen in the thickness direction $(Z)$. Therefore, only specimens manufactured along the $\mathrm{X}$ and $\mathrm{Y}$ directions were studied.

This way, the tested materials were classified according to their manufacturing technology. Table 1 summarizes the manufacturing technology, printer model, material commercial denomination and type, and the denomination throughout the paper of the materials used to carry out the tests in this work.

The specimens were created with the material recommended by each manufacturer for their printer. Manufacturers indicate the printing parameters and optimize the performance of their printers according to the materials they supply. The combination of each printer and material provided specimens that showed different behaviour. For example, DLP and SLA are similar 3D printing techniques, although the former uses a digital projector screen to flash an ultraviolet light which cures the photopolymer resins, and the latter a directed laser. However, different mechanical behaviours of the specimens were observed from the results of the study.

Tensile tests and bending tests were conducted on a population of specimens of the aforementioned materials and manufacturing technologies. Tensile tests were performed following the ASTM D638 standard [42]. Bending tests were conducted according to the ISO 178:2019 standard [43], which is equivalent to ASTM D790 [44]. Differences between the two directions on the plane of the printer tray, $X$ and $Y$, and the perpendicular direction to it, $Z$, were evaluated. Therefore, it was necessary to have specimens for each manufacturing direction according to the $\mathrm{X}, \mathrm{Y}, \mathrm{Z}$ axes. Figure 1 shows three different positions of a part on the printer tray. The red faces represent the printing layers in the three previously mentioned directions during the manufacturing process.

Five specimens of each material manufactured in the three printing directions were tested. This way, 30 specimens were tested for each material and 270 specimens should have been tested. However, as mentioned before, the PMMA specimens could only be manufactured in the $X$ and $Y$ directions. Furthermore, due to supply problems, specimens manufactured with SLA2 material were not evaluated in traction tests in the $\mathrm{Y}$ printing direction. Consequently, the results obtained with 255 specimens are included in this paper. As indicated before, specimens were supplied by the printer manufacturers. This way, specimens were created by the printer manufacturer with the material supplied and recommended for their printer. Manufacturers optimized their printer's performance according to the indicated materials. The only common parameter in 
Table 1 Specimen manufacturing technologies, printer model, materials, and material denomination

\begin{tabular}{|c|c|c|c|c|}
\hline $\begin{array}{l}\text { Manufacturing } \\
\text { technology }\end{array}$ & $\begin{array}{l}\text { Printer model/milling machine } \\
\text { model }\end{array}$ & $\begin{array}{l}\text { Material (commercial } \\
\text { denomination) }\end{array}$ & Material type & $\begin{array}{l}\text { Material } \\
\text { denomination }\end{array}$ \\
\hline Polyjet & Objet 260 & MED 610 & Photopolymer & Polj \\
\hline Selective Laser & RICOH AM S5500P & Ricoh AM S5500P (PA12) & Polyamide 12 & SLS1 \\
\hline Sintering & EOS P110 & P2200 (P12) & Polyamide 12 & SLS2 \\
\hline Digital Light & Voco Solflex 650 & V-Print Ortho & Methacrylate-based resin & DLP1 \\
\hline \multirow[t]{2}{*}{ Processing } & Voco Solflex 650 & V-Print Splint & Methacrylate-based resin & DLP2 \\
\hline & Microlay versus 385 & Freeprint Splint & $\begin{array}{l}\text { Mixture of acrylic/ } \\
\text { methacrylic resins }\end{array}$ & DLP3 \\
\hline \multirow[t]{2}{*}{ Stereolithography } & XFAB 2500PD & DWS DS5000 & Acrylic Resin & SLA1 \\
\hline & Formlab Form 2 & Dental LT Clear & Acrylic Resin & SLA2 \\
\hline Milling & $\begin{array}{l}\text { Roland DWX-52DC (milling } \\
\text { machine) }\end{array}$ & PMMA & poly methyl methacrylate & PMMA \\
\hline
\end{tabular}

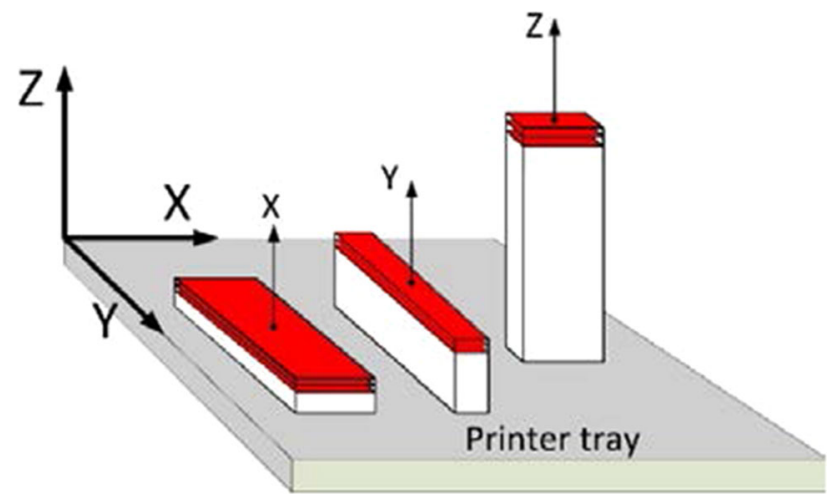

Figure 1 Orientation of the specimens on the print tray.

all cases was layer thickness, which was equal to $100 \mu \mathrm{m}$ in all printed specimens.

A test bench designed by this research team was used to carry out this work. The bench is composed of a frame with a fixed and a mobile plate. Specimens were tested as shown in Figs. 2 and 3. The movable plate is the component used to apply the deformation to the specimens. The excitation to the parts to be tested is generated by a hydraulic cylinder controlled by a servo-valve. This way, a controlled displacement or force is transmitted to the movable plate. A high accuracy displacement sensor and a force sensor were used to measure de elongation and applied forces, respectively.

\section{Tensile tests}

In the tensile tests, a progressively increasing force was applied to the ends of the specimens by means of two holder clamps. The lower clamp remained fixed while the upper one moved at a constant speed of $0.1 \mathrm{~mm} / \mathrm{min}$ (Fig. 2a). The applied force and the elongation were continuously recorded with a load cell and a linear variable differential transformer (LVDT), respectively. The tensile tests continued until the specimens broke (Fig. 2b). This way, the stress that the material could withstand before complete failure took place was measured.

Three key parameters to analyse material behaviour were obtained with these tests:

1. Maximum allowable stress.

2. Stress recorded at the moment of fracture, called rupture stress.

3. Deformation suffered by the specimen before fracture.

All the specimens were manufactured according to the ASTM D638 standard (see Fig. 2c). The dimensions of the specimens are shown inTable 2 .

\section{Bending tests}

In the bending tests, each specimen was supported at both ends as shown in Fig. 3a. Next, a progressively increasing force was applied to the midpoint of the top face of the specimen, producing continuous transversal displacement and causing the curvature of the sample (Fig. 3b). The tests continued until specimen fracture took place. The force acting on the material and the displacements of the midpoint were recorded simultaneously.

The specimens and the supports were manufactured according to the ISO 178 standard (Fig. 3c). The 
Figure 2 Tensile test.

a Specimen in the test bench.

b Rupture of the specimen.

c Specimen measurements.

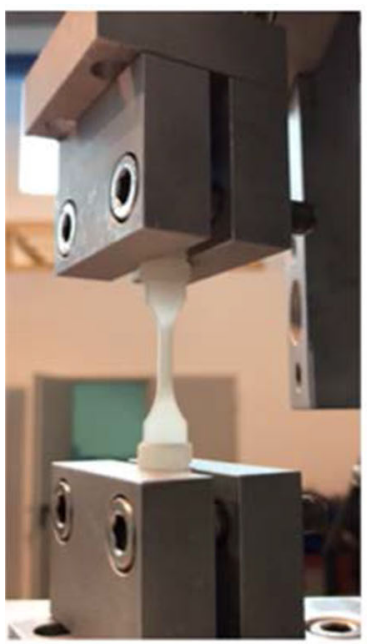

(a)

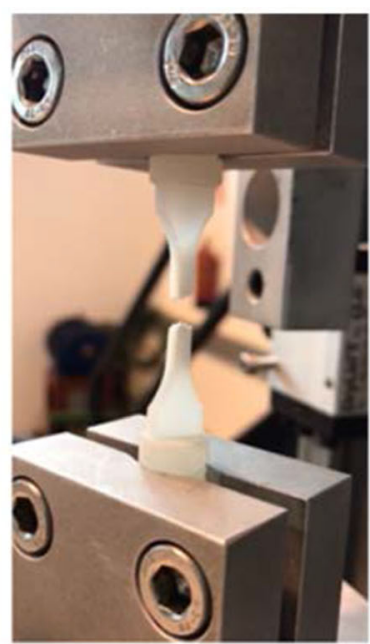

(b)

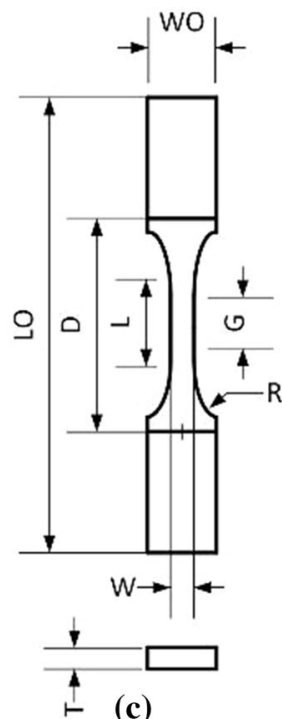

(c)

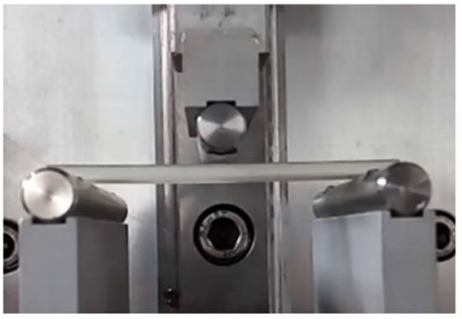

(a)

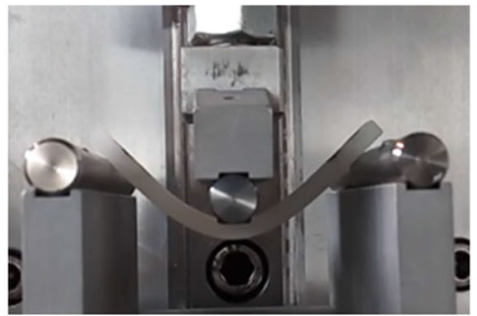

(b)

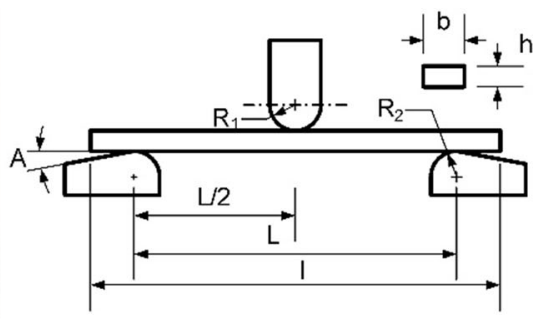

(c)

Figure 3 Bending test. a Specimen in the test bench. b Maximum allowable specimen deflection. c Specimen, supports, and loading pin measurements.

Table 2 Specimen dimensions for the tensile test according to ASTM D638-02a

$\mathrm{T}-$ Thickness

$3.20 \mathrm{~mm}$

W - Width of the narrow section

$\mathrm{L}$ - Length of the narrow section

WO - Total width

LO - Total length

D - Distance between grips

$\mathrm{G}$ - Length of calibrated section

$\mathrm{R}$ - Rounding radius
In this case, four key parameters to analyse material properties were obtained:

1. Maximum flexural stress.

2. Stress recorded at failure in bending, called rupture flexural stress.

3. Flexural modulus.

4. Deformation suffered by the specimens before fracture in the transversal plane.

\section{Results and discussion}

thickness (h), width (b) and length (l) of the specimens were 4,10 , and $80 \mathrm{~mm}$, respectively. The dimensions of the supports and the loading pin were the following: the length between the supports (L) was $64 \mathrm{~mm}$, the punch and supporting piece radius $\left(R_{1}\right.$ and $\left.R_{2}\right)$ were $5 \mathrm{~mm}$ and the relief angle (A) was $\geq 5^{\circ}$.
A total of nine materials suitable to be used in the dental industry were tested. Eight of them are used in 3D printing technologies and one is used in milling technology. As mentioned before, the specimens were subjected to tensile and bending tests. Results are shown next. 


\section{Tensile test results}

In these tests, total force applied to the specimens as well as elongation were recorded. The initial dimensions of the narrow section of each of the specimens were measured with a Vernier caliper. In addition, it was verified that all dimensional tolerances were fulfilled. Figure 4 shows a sample of the results obtained with a specimen of each material.

The total deformation of the specimens were recorded in these traction tests, i.e. the change in distance between grips were measured. These tests were conducted as an initial evaluation of the specimens. As we did not measure the deformations in the narrow section, we cannot include the strain in these figures. On one hand, it can be seen that SLA2 and PMMA materials had the highest values for allowable stress and rupture stress. On the other hand, the SLS1 material provided lower values for rupture and maximum allowable stress. Besides, SLS2 showed great tenacity in all directions, but its maximum allowable stress was medium-low. Interestingly, the SLS1 tenacity was high in the $X$ and $Y$ direction but very low in the $Z$ direction. The average maximum allowable stress and rupture stress of the specimens of each material and printing direction as well as the maximum and minimum values obtained in the tests are shown in Figs. 5 and 6.

It can be observed that SLA2 and PMMA reached the maximum allowable stress and rupture stress. Both materials showed brittle behaviour. There were no big differences between the three printing directions. DLP materials showed a quite homogeneous performance, being slightly better in the $Z$ direction.

Tables 3 and 4 show the average results of maximum allowable stress and rupture stress obtained in tensile tests of specimens of each one of the materials in the three printing directions $X, Y, Z$ as well as their
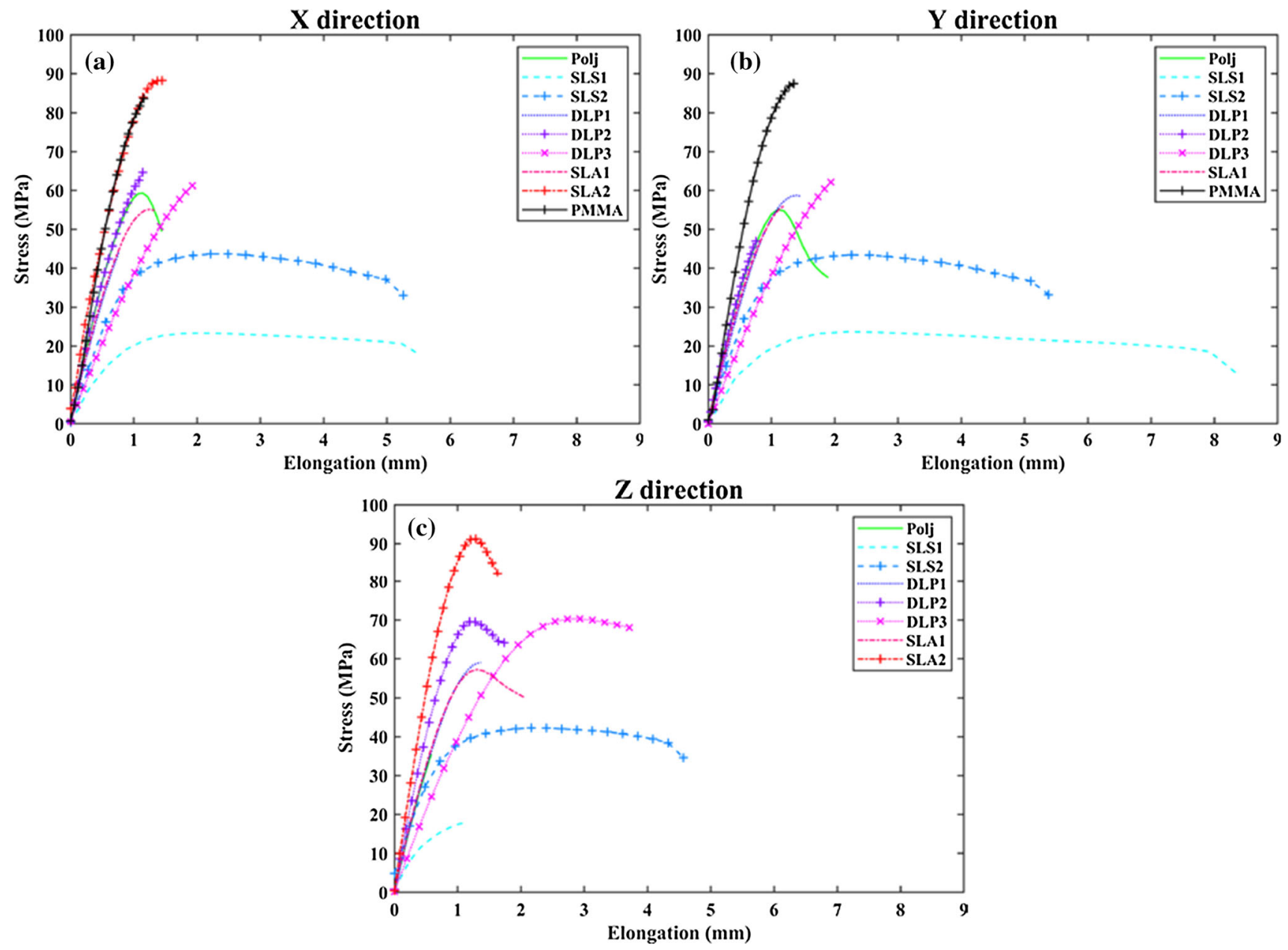

Figure 4 Tensile test results with a specimen of each material. 

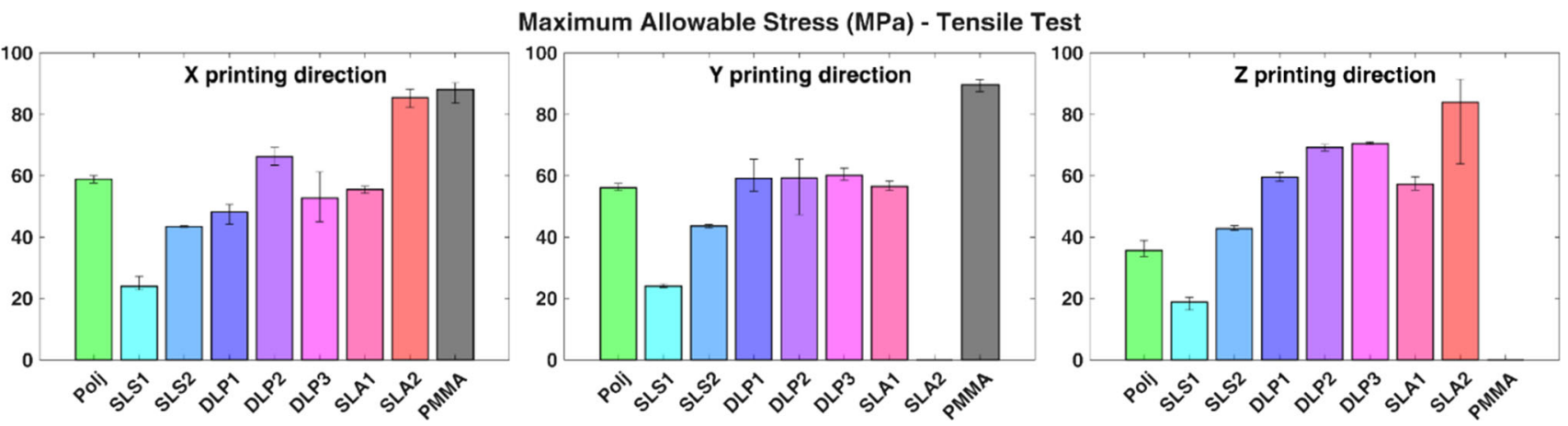

Figure 5 Average maximum allowable stress for each material in the $X, Y$ and $Z$ printing directions.
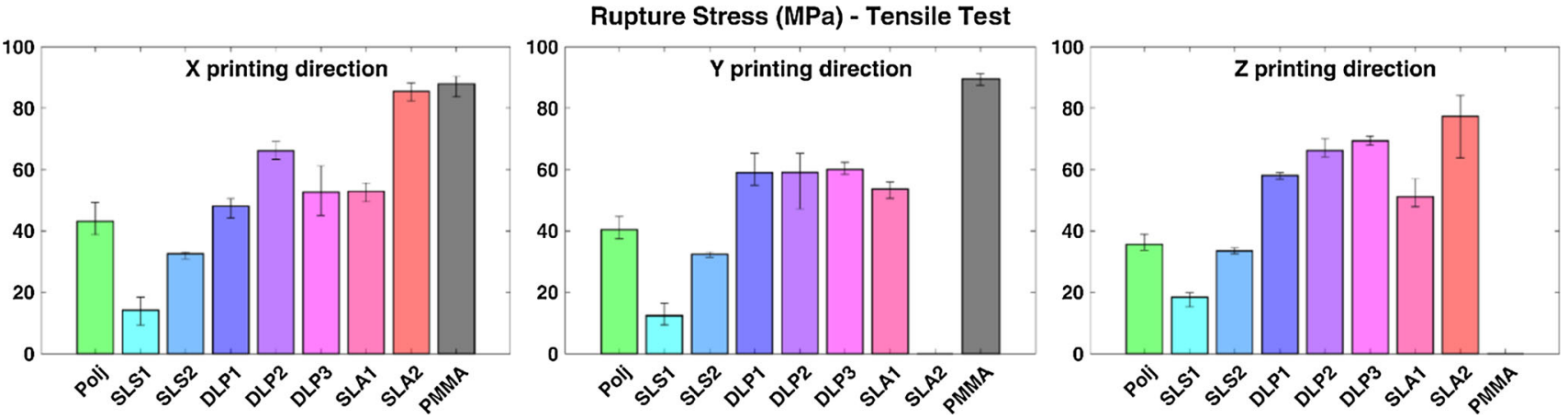

Figure 6 Average rupture stress for each material in the $X, Y$ and $Z$ printing directions.

Table 3 Maximum allowable stress (UTS) and standard deviation (SD) of the tensile test

\begin{tabular}{lccc}
\hline & UTS X $[\mathrm{MPa}]$ & UTS Y $[\mathrm{MPa}]$ & UTS Z $[\mathrm{MPa}]$ \\
\hline Polyjet & $58.87 \pm 1.12$ & $56.03 \pm 0.86$ & $35.64 \pm 2.06$ \\
SLS1 & $23.94 \pm 1.87$ & $23.98 \pm 0.60$ & $18.76 \pm 1.78$ \\
SLS2 & $43.47 \pm 0.16$ & $43.65 \pm 0.49$ & $42.79 \pm 0.58$ \\
DLP1 & $48.13 \pm 2.74$ & $59.09 \pm 3.82$ & $59.49 \pm 1.20$ \\
DLP2 & $66.12 \pm 2.58$ & $59.25 \pm 7.20$ & $69.20 \pm 1.06$ \\
DLP3 & $52.69 \pm 6.05$ & $59.99 \pm 2.09$ & $70.48 \pm 0.35$ \\
SLA1 & $55.53 \pm 0.88$ & $56.48 \pm 1.25$ & $57.19 \pm 1.60$ \\
SLA2 & $85.44 \pm 2.98$ & - & $83.2 \pm 11.30$ \\
PMMA & $88.08 \pm 2.58$ & $89.61 \pm 1.58$ & - \\
\hline
\end{tabular}

standard deviations (Values are presented as means $\pm \mathrm{SD}$ ). As mentioned before, no results are available for the $Y$-axis of the SLA2 material due to lack of supply of the specimen and for the Z-axis of the PMMA material due to the impossibility of producing milled specimens in this direction.

Concerning deformation, Table 5 shows the average elongation at maximum stress (EMS) and elongation at the rupture point (ERP) in the three printing
Table 4 Average fracture stress (FS) and standard deviation (SD) of the tensile test

\begin{tabular}{lccc}
\hline & FS X $[\mathrm{MPa}]$ & FS Y $[\mathrm{MPa}]$ & FS Z $[\mathrm{MPa}]$ \\
\hline Polyjet & $43.16 \pm 3.99$ & $40.37 \pm 2.66$ & $35.61 \pm 2.06$ \\
SLS1 & $14.13 \pm 4.25$ & $12.76 \pm 3.52$ & $18.37 \pm 1.97$ \\
SLS2 & $32.54 \pm 0.98$ & $32.36 \pm 0.78$ & $33.54 \pm 0.71$ \\
DLP1 & $48.13 \pm 2.74$ & $59.02 \pm 3.83$ & $58.08 \pm 0.87$ \\
DLP2 & $66.11 \pm 2.59$ & $59.14 \pm 7.11$ & $66.27 \pm 2.64$ \\
DLP3 & $52.69 \pm 6.05$ & $59.99 \pm 2.09$ & $69.38 \pm 1.17$ \\
SLA1 & $52.89 \pm 2.47$ & $53.73 \pm 2.22$ & $51.16 \pm 3.63$ \\
SLA2 & $85.44 \pm 2.98$ & - & $77.42 \pm 7.95$ \\
PMMA & $87.95 \pm 2.52$ & $89.47 \pm 1.60$ & - \\
\hline
\end{tabular}

directions. In brittle specimens, both values are quite similar, such as in DLP and SLA specimens. As shown in Fig. 4, the highest elongations were achieved with the SLS manufacturing technology.

\section{Bending test results}

In these three-point flexural tests, total force applied to specimens as well as deflections of test specimens at midspan were recorded. With these data, flexural 
Table 5 Elongation at maximum stress (EMS) and elongation at rupture point (ERP)

\begin{tabular}{|c|c|c|c|c|c|c|}
\hline & EMS X [mm] & ERP. X [mm] & EMS. Y $[\mathrm{mm}]$ & ERP Y $[\mathrm{mm}]$ & EMS Z [mm] & $\mathrm{ERP} Z[\mathrm{~mm}]$ \\
\hline Polyjet & 1.092 & 1.604 & 1.109 & 1.729 & 0.594 & 0.595 \\
\hline SLS1 & 2.097 & 6.876 & 2.258 & 9.812 & 1.393 & 1.488 \\
\hline SLS2 & 2.407 & 5.44 & 2.338 & 5.281 & 2.387 & 4.935 \\
\hline DLP1 & 0.873 & 0.873 & 1.292 & 1.32 & 1.373 & 1.653 \\
\hline DLP2 & 1.243 & 1.251 & 1.077 & 1.094 & 1.24 & 1.518 \\
\hline DLP3 & 1.548 & 1.548 & 1.819 & 1.819 & 2.862 & 3.334 \\
\hline SLA1 & 1.296 & 1.613 & 1.292 & 1.636 & 1.289 & 1.971 \\
\hline SLA2 & 1.231 & 1.241 & - & - & 1.152 & 1.474 \\
\hline PMMA & 1.394 & 1.43 & 1.514 & 1.529 & - & - \\
\hline
\end{tabular}

stresses and flexural strains were obtained. Figure 7 shows a sample of the results obtained in these flexural tests with a specimen of each material.

Figures 8 and 9 show the average maximum stress and rupture stress for each of the materials, as well as the maximum and minimum values obtained in these tests. The average values and standard deviations are shown in Tables 6 and 7.

It should be noted that the material with the highest maximum stress and rupture stress in the
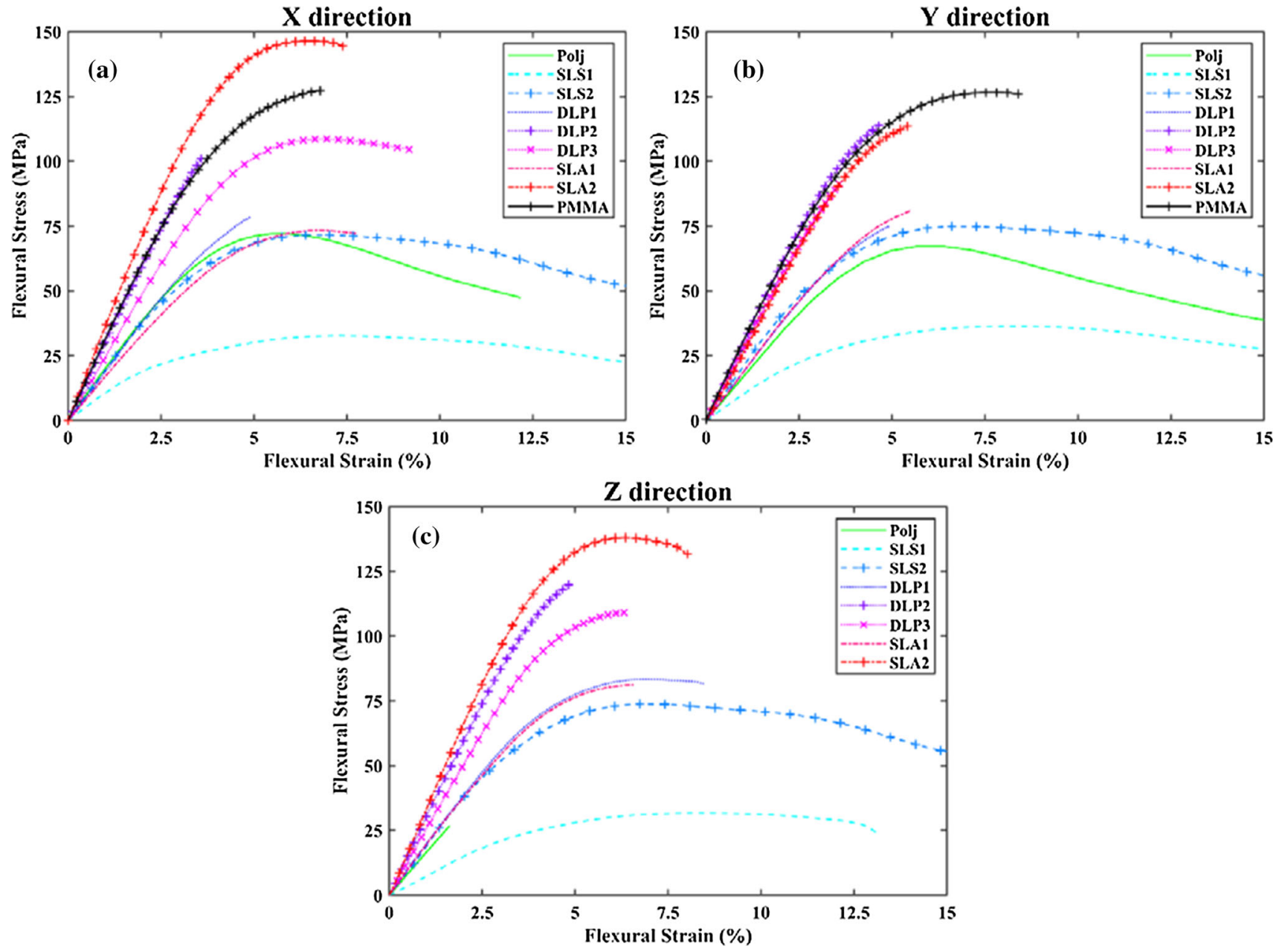

Figure 7 Flexural test results with a specimen of each material. 

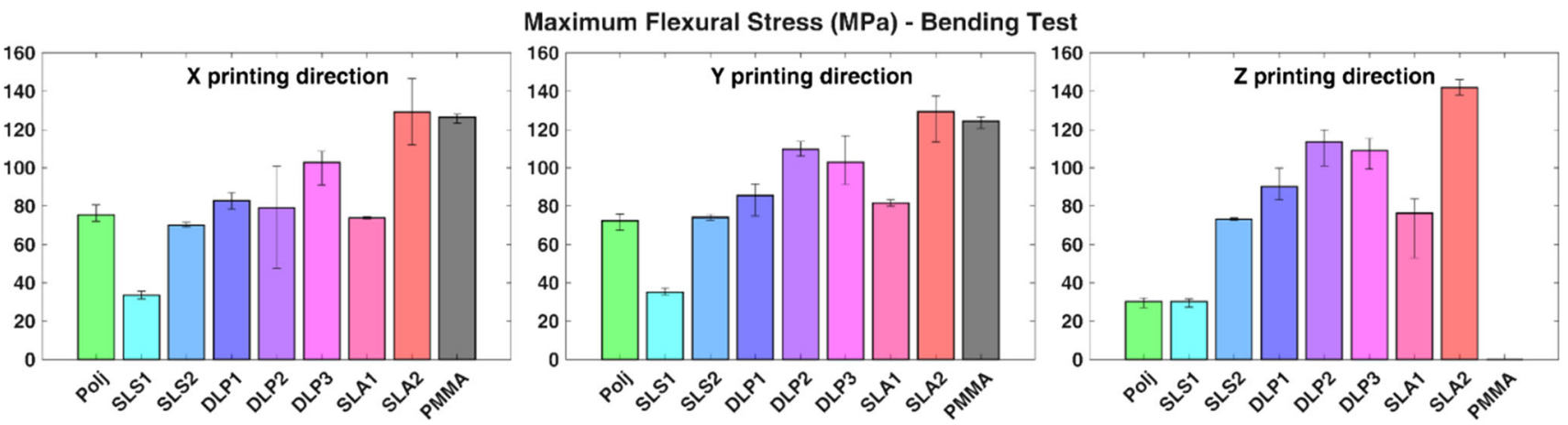

Figure 8 Average maximum flexural stress for each material in the $X, Y$ and $Z$ printing directions.
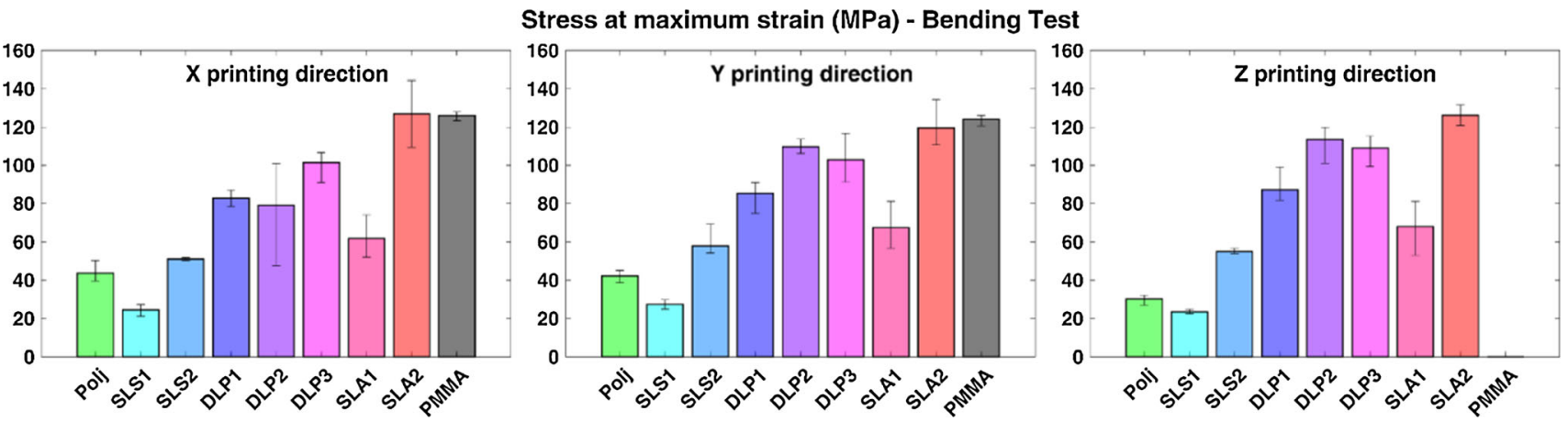

Figure 9 Average stress at maximum strain for each material in the $X, Y$ and $Z$ printing directions.

Table 6 Average results of maximum stress and standard deviation for each manufacturing direction of the specimens

\begin{tabular}{lccc}
\hline & UTS X $[\mathrm{MPa}]$ & UTS Y $[\mathrm{MPa}]$ & UTS Z [MPa] \\
\hline Polyjet & $75.38 \pm 3.27$ & $72.46 \pm 3.84$ & $30.05 \pm 2.19$ \\
SLS1 & $33.42 \pm 1.52$ & $35.03 \pm 1.67$ & $30.09 \pm 1.82$ \\
SLS2 & $70.18 \pm 0.98$ & $74.08 \pm 1.12$ & $73.24 \pm 0.43$ \\
DLP1 & $82.81 \pm 3.04$ & $85.42 \pm 7.34$ & $89.99 \pm 6.61$ \\
DLP2 & $79.06 \pm 27.52$ & $109.73 \pm 3.63$ & $113.61 \pm 7.31$ \\
DLP3 & $102.68 \pm 7.59$ & $102.74 \pm 11.95$ & $109.06 \pm 6.11$ \\
SLA1 & $73.89 \pm 0.44$ & $81.54 \pm 1.74$ & $76.25 \pm 13.03$ \\
SLA2 & $129.17 \pm 24.42$ & $129.45 \pm 13.74$ & $141.97 \pm 5.54$ \\
PMMA & $126.46 \pm 2.03$ & $124.26 \pm 2.66$ & - \\
\hline
\end{tabular}

bending tests was SLA2 and PMMA, having similar values in all printing directions. SLS materials reached low maximum stress values, but rupture did not take place before maximum measured strain. This way, the SLS material again proved to be the most ductile of all the tested materials.

Figure 10 and Table 8 show the flexural modulus (FM) of the materials. It can be seen that the SLA2 material provided a high flexural modulus value
Table 7 Average results of stress at maximum strain and standard deviation for each manufacturing direction of the specimens

\begin{tabular}{lccc}
\hline & FS X $[\mathrm{MPa}]$ & FS Y $[\mathrm{MPa}]$ & FS Z $[\mathrm{MPa}]$ \\
\hline Polyjet & $43.71 \pm 4.85$ & $42.19 \pm 3.40$ & $30.05 \pm 2.19$ \\
SLS1 & $24.39 \pm 2.51$ & $27.37 \pm 2.08$ & $23.31 \pm 0.92$ \\
SLS2 & $50.94 \pm 0.61$ & $57.91 \pm 6.49$ & $54.99 \pm 1.10$ \\
DLP1 & $82.81 \pm 3.04$ & $85.31 \pm 7.22$ & $87.04 \pm 6.86$ \\
DLP2 & $79.06 \pm 27.52$ & $109.73 \pm 3.63$ & $113.61 \pm 7.31$ \\
DLP3 & $101.42 \pm 6.56$ & $102.74 \pm 11.95$ & $109.06 \pm 6.11$ \\
SLA1 & $61.90 \pm 10.31$ & $67.41 \pm 9.04$ & $68.10 \pm 13.14$ \\
SLA2 & $126.88 \pm 24.79$ & $119.58 \pm 12.99$ & $126.17 \pm 7.73$ \\
PMMA & $126.06 \pm 1.93$ & $124.15 \pm 2.55$ & - \\
\hline
\end{tabular}

regardless of the printing directions. On the other hand, the SLS1 printing material had the lowest flexural modulus value of all the tested materials and printing technologies.

Table 9 shows the bending deformation measured in these tests. The maximum strain was limited to $15 \%$. In this table, XM, YM and ZM columns include the deformations measured at maximum stress with the specimens manufactured in the $X, Y$ and 
Flexural Modulus (MPa) - Bending Test
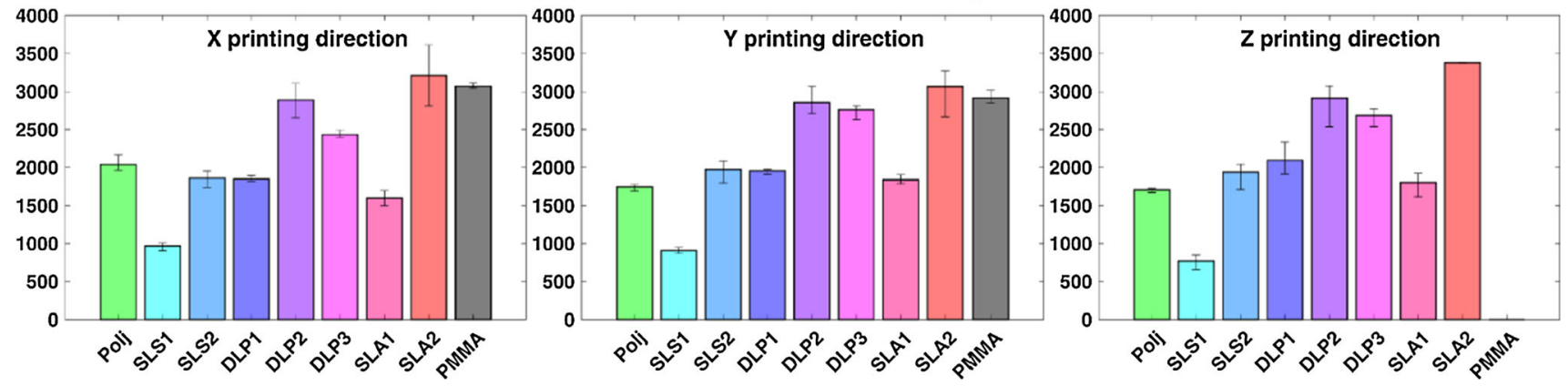

Figure 10 Flexural modulus for each material in the $X, Y$ and $Z$ printing directions.

Table 8 Average results of the flexural modulus and standard deviation values for each manufacturing direction of the specimens

\begin{tabular}{lccc}
\hline & FM X $[\mathrm{MPa}]$ & FM Y $[\mathrm{MPa}]$ & FM Z [MPa $]$ \\
\hline Polyjet & $2039 \pm 81$ & $1747 \pm 38$ & $1707 \pm 27$ \\
SLS1 & $967 \pm 40$ & $908 \pm 39$ & $766 \pm 71$ \\
SLS2 & $1863 \pm 89$ & $1973 \pm 117$ & $1935 \pm 129$ \\
DLP1 & $1850 \pm 30$ & $1953 \pm 29$ & $2092 \pm 165$ \\
DLP2 & $2887 \pm 202$ & $2854 \pm 141$ & $2914 \pm 233$ \\
DLP3 & $2433 \pm 38$ & $2760 \pm 73$ & $2685 \pm 90$ \\
SLA1 & $1599 \pm 92$ & $1837 \pm 42$ & $1803 \pm 117$ \\
SLA2 & $3213 \pm 570$ & $3069 \pm 348$ & $3383 \pm 12$ \\
PMMA & $3071 \pm 29$ & $2917 \pm 68$ & - \\
\hline
\end{tabular}

$Z$ printing directions, respectively. Similarly, $X R, Y R$ and $Z R$ are the deformations measured at maximum strain. It can be seen that the DLP materials had relatively low deformation values in all printing directions. In contrast, the SLS1 and SLS2 materials had large deformation values in all printing directions at maximum stress and rupture stress values. These materials are among the most ductile ones in the selected population of specimens. As it was pointed out before, these materials did not break at maximum deformation in some tests. It is worth highlighting the behavior of Polyjet. The maximum strain reached with this material was very high in the $X$ and $Y$ printing direction. However, the maximum allowable strain in the $Z$ direction was extremely low.

It can be seen that some materials seem to have a brittle behaviour, while others show a more ductile behaviour. In ductile materials, there is a significant deformation before rupturing, which alerts of an imminent fracture. This way, ductile materials can prevent pieces from breaking unexpectedly in the mouth. On the other hand, fragile materials break suddenly with very little elastic deformation and, therefore, without prior warning.

A further study of the test results can contribute to gaining a better insight into these materials. Thus, an analysis and a discussion of the results obtained from the conducted tensile and bending tests are carried out next.

Figures 11 and 12 show the maximum allowable stress vs flexural modulus and vs the stress at the maximum strain, respectively, in the bending tests in the three printing directions. Average values are marked with a ' + ' symbol. In brittle materials, both
Table 9 Deformation at maximum stress $(-\mathrm{M})$ and maximum strain $(-\mathrm{R})$

\begin{tabular}{lllllll}
\hline & Def. XM [\%] & Def. XR [\%] & Def. YM [\%] & Def. YR [\%] & Def. ZM [\%] & Def. ZR [\%] \\
\hline Polyjet & 5.66 & 13.84 & 6.13 & 15 & 1.8 & 1.8 \\
SLS1 & 7.56 & 15 & 8.17 & 14.53 & 8.46 & 14.13 \\
SLS2 & 6.84 & 15 & 7.17 & 15 & 7.28 & 15 \\
DLP1 & 6.33 & 6.33 & 6.49 & 6.56 & 6.91 & 8.61 \\
DLP2 & 3.03 & 3.03 & 4.92 & 4.92 & 4.96 & 4.96 \\
DLP3 & 5.86 & 6.67 & 4.65 & 4.65 & 5.48 & 5.48 \\
SLA1 & 7.34 & 12.18 & 6.82 & 11.75 & 6.08 & 8.64 \\
SLA2 & 6.43 & 7.38 & 6.06 & 7.99 & 6.39 & 10.33 \\
PMMA & 6.76 & 7 & 6.83 & 6.97 & - & -
\end{tabular}



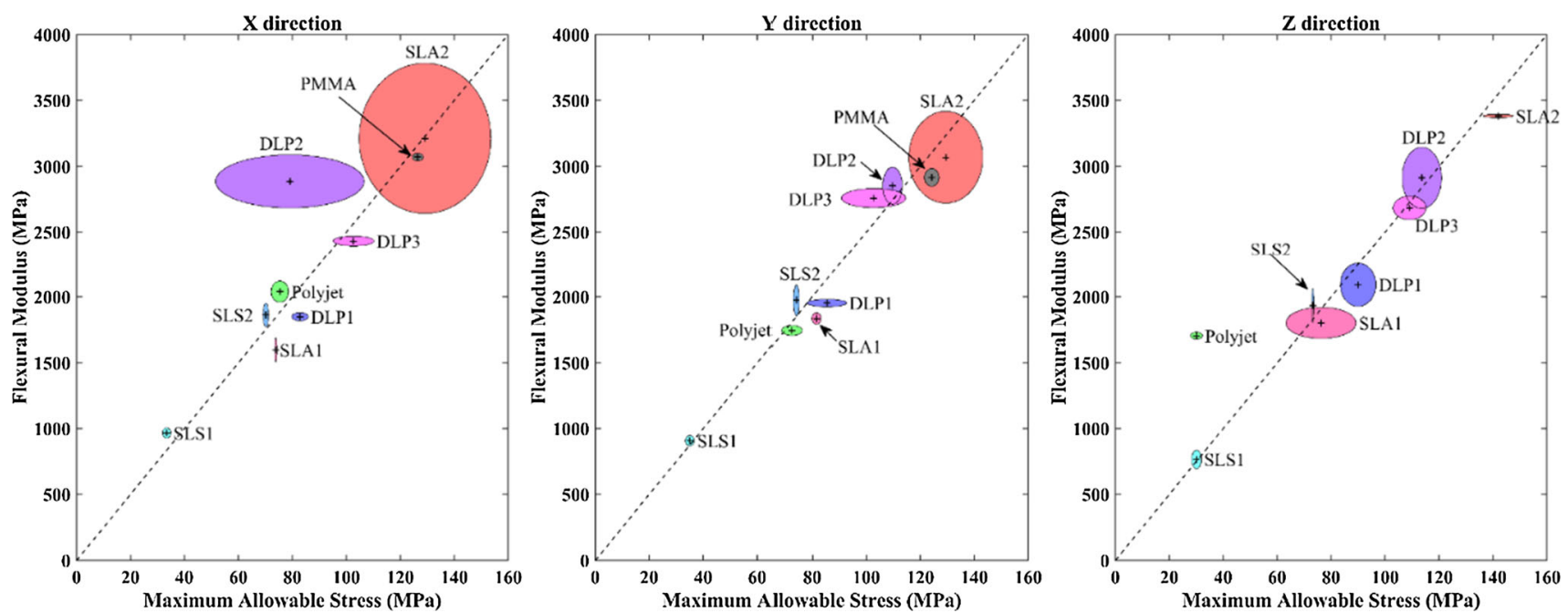

Figure 11 Maximum allowable stress versus flexural modulus.
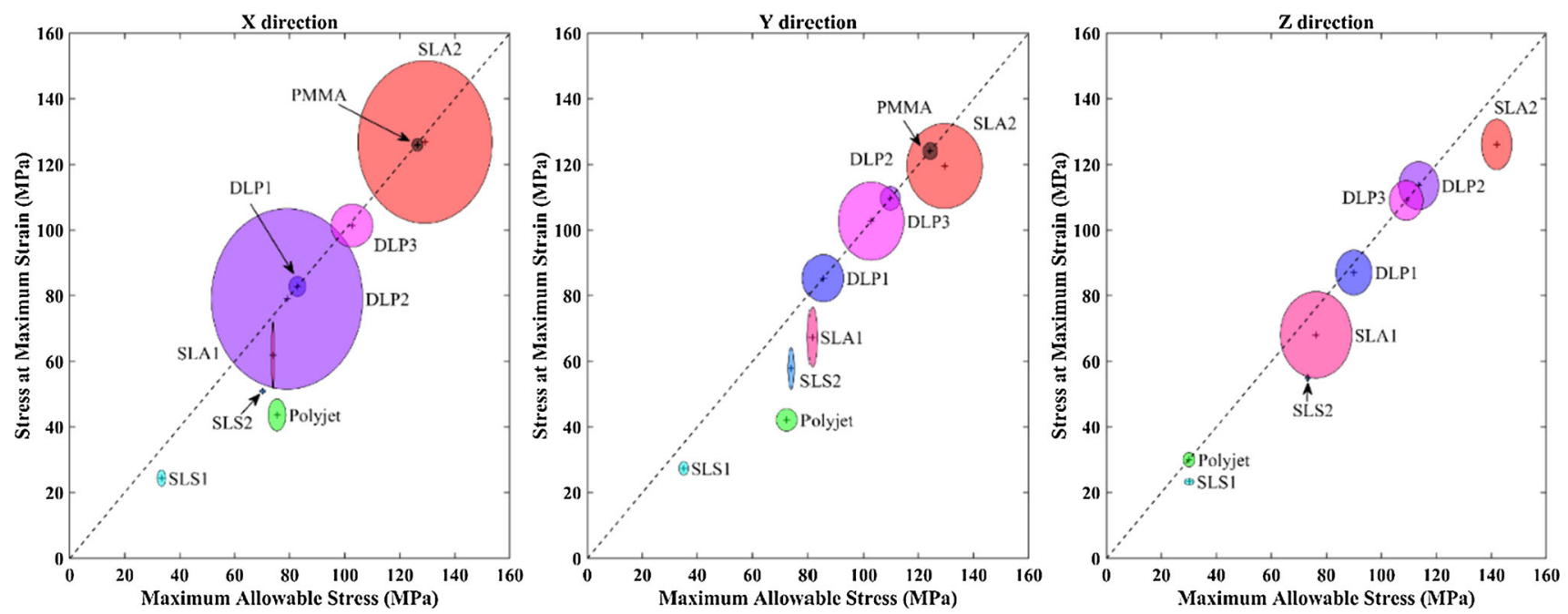

Figure 12 Maximum allowable stress versus stress at maximum strain.

values are quite similar and the average value is located close to the diagonal of the box. On the contrary, the further away from the average value from the diagonal is, the more ductile the behaviour of the material is. Furthermore, the length of the axes of the coloured ellipses represents the standard deviations of the measured values.

It can be seen that the highest maximum allowable stresses were reached with SLA2 and PMMA materials while the lowest values were reported with SLS1 specimens. SLS1, SLS2, Polyjet, and PMMA specimens showed highly repetitive results. According to these low standard deviation values, devices manufactured with this material will show a homogenous performance. On the contrary, SLA2 and DLP2 showed a higher dispersion of the results in the bending tests carried out in the $\mathrm{X}$ and $\mathrm{Y}$ direction. In these cases, an appropriate design of the devices taking into account the expected loads on the manufactured parts might reduce the effects of bending stresses.

Next, Fig. 13 shows strain at yield point vs maximum strain in the bending tests. Average values above the diagonal indicate a ductile behaviour of the materials.

It can be observed that Polyjet in the $X$ and $Y$ directions and SLS2 and SLS1 in all cases showed great deformation levels, being the most ductile materials. On the contrary, DLP materials showed lower admissible strain rates. In most cases, the dispersion 

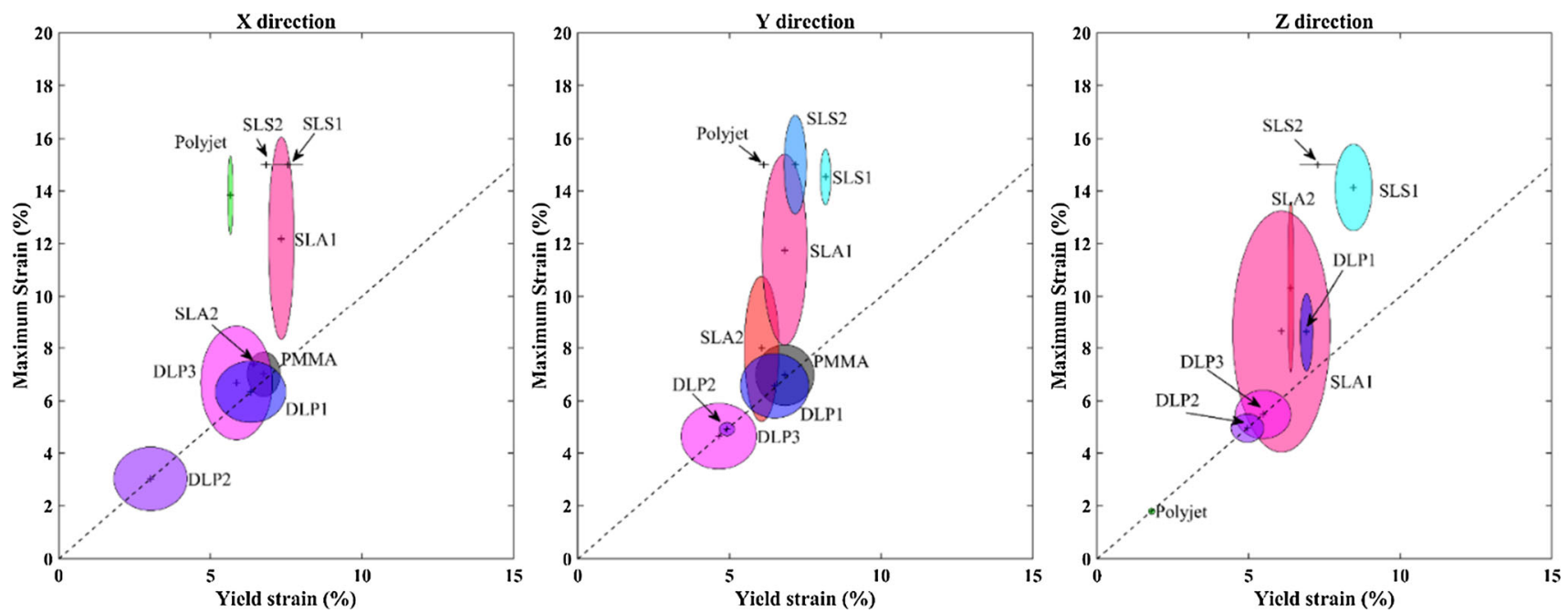

Figure 13 Yield strain versus maximum strain.

of the yield strain values was low. However, high standard deviation values were observed for the maximum strain values. This way, SLA1 and DLP3 showed great dispersion in the measured values.

Materials such as PMMA, SLA2 and DLP2 have intermediate mechanical behaviour compared to the other materials, making them preferable to manufacture dental devices. Results show heterogeneous behaviour in the tested biocompatible materials.

Regarding the influence of printing direction, Table 10 shows the relative change in the percentage of Maximum Allowable Stress (MAS) measured in the $Y$ and $Z$ directions with respect to the values obtained in the $X$ direction in the bending tests.

Results suggest that the printing direction influences the results obtained in some cases. This way, specimens manufactured with Polyjet and SLS1 showed a degraded performance in the $Z$ direction in traction tests. On the contrary, DLP specimens printed in the $Z$ direction provided better results. Results obtained with SLS2, PMMA and SLA showed that the mechanical behaviour of the tested specimens was homogeneous regardless of the printing direction.

Table 11 shows that the estimated flexural modulus (FM) obtained from the tests is significantly affected by the printing directions. In some cases, the flexural modulus in the $X$ direction was the highest one, such as Polyjet and SLS1. On the other hand, in DLP1, DLP3 and SLA1, the highest value of the flexural modulus was measured in the $\mathrm{Z}$ direction, being more than $10 \%$ higher compared to the other two directions.

It can be observed that, in some cases, the printing direction significantly changes the mechanical properties of the specimens. This fact might be due to a poor connection between the printing layers. Therefore, if a dental splint made of Polijet or SLS1
Table 10 Comparison of maximum allowable stresse $\mathrm{s}$

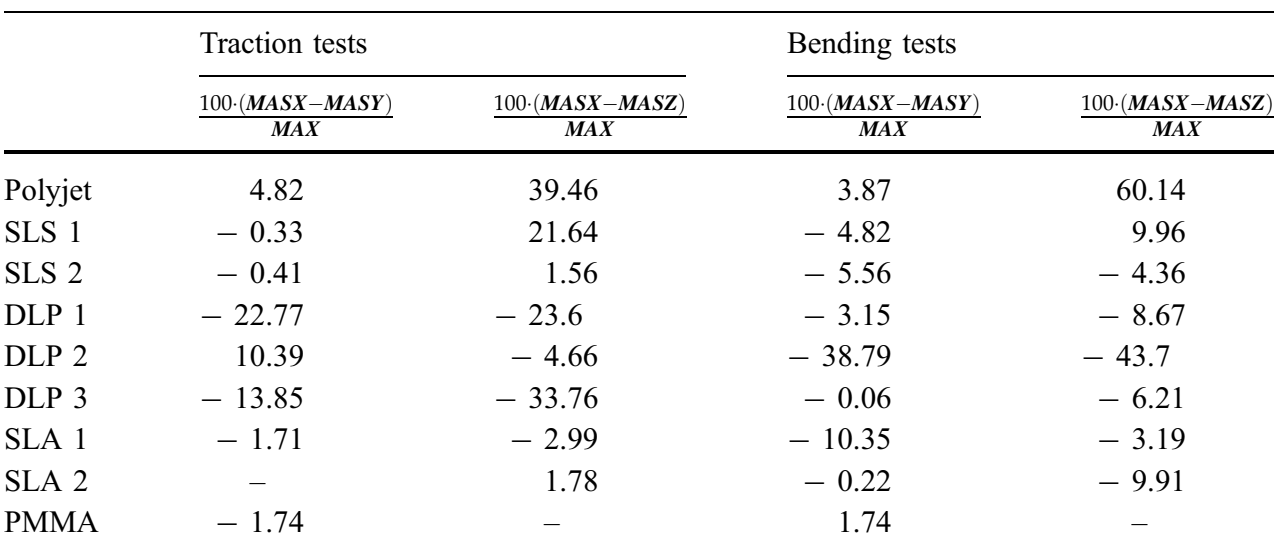


Table 11 Comparison of flexural modulus values

\begin{tabular}{lcc}
\hline Bending tests & & \\
\hline & $\frac{100 \cdot(\boldsymbol{F M} \boldsymbol{X}-\boldsymbol{F M} \boldsymbol{M} \boldsymbol{Y})}{\boldsymbol{F M} \boldsymbol{X}}$ & $\frac{100 \cdot(\boldsymbol{F M} \boldsymbol{X}-\boldsymbol{F M} \boldsymbol{Z})}{\boldsymbol{F M} \boldsymbol{X}}$ \\
\hline Polyjet & 14.32 & 16.28 \\
SLS 1 & 6.1 & 20.79 \\
SLS 2 & -5.9 & -3.86 \\
DLP 1 & -5.57 & -13.1 \\
DLP 2 & 1.14 & -0.94 \\
DLP 3 & -13.4 & -10.4 \\
SLA 1 & -14.9 & -12.8 \\
SLA 2 & 4.48 & -5.29 \\
PMMA & 5.01 & - \\
\hline
\end{tabular}

materials is printed in the Z-direction, the forces required for removal of the splint may cause it to break easily due to retention of the device in the dental arches. In consequence, it is recommended to print the devices in a direction in which the device is not strained to avoid this problem. However, if there are forces in all directions, the design must be carried out taking into account the manufacturing direction.

Finally, although the material is the same in some AM technologies, "acrylic resin," the manufacturers use different percentages of compositions according to the technology used. Therefore, the results obtained in this paper are related to the materials provided by the printer manufacturers. However, the study of the influence of material composition is out of the scope of this paper.

In summary, when designing an intraoral device, it is advisable to take into account the efforts to which it will be subjected and their directions, as well as the deformations allowed for proper operation. With this information, the appropriate manufacturing technology and material can be selected.

\section{Conclusions}

This paper focuses on the influence of the manufacturing process and printing direction on the properties of parts manufactured with a wide range of biocompatible materials used in dentistry. Specimens of these materials have been characterized by conducting tensile and bending tests.

From the analysis of the obtained results, it can be concluded that:
- Specimens manufactured with Stereolithography (SLA) and milling (polymethyl methacrylate PMMA) achieved high maximum allowable and rupture stress values. Particularly, SLA2 showed a high flexural modulus value in all printing directions.

- Polyjet printing and Selective Laser Sintering (SLS) technologies led to force-deformation curves with low maximum stress and high deformation values.

- The Digital Light Processing (DLP) technology showed intermediate and homogeneous performance compared with the other technologies regardless of the material used.

- Printing direction significantly influences the mechanical properties of the manufactured specimens in some cases. This way, specimens manufactured with Polyjet and SLS1 showed a degraded performance in the $\mathrm{Z}$ direction. On the contrary, the performance of SLS2, PMMA, and SLA was similar in all printing directions.

Lastly, the final selected combination of biocompatible material and printing technology should take into account the value and direction of the expected loads on the manufactured devices. In general, the best materials for this type of application should have high toughness with a good balance between strength and elasticity, such as in the case of SLS2 in all printing directions and DLP3 and SLA2 in the X-direction. It should be noted that a dental device might not work properly when a permanent deformation has been caused. This work will contribute to gaining insights into the best possible combination of printing technology, printing direction, and biocompatible material for the manufacture of dental devices. Furthermore, cost and printing times should also be evaluated to select the most suitable combination of factors. Future works will focus on evaluating the change in the properties of the printed parts over time depending on the materials used and the environmental conditions in which they are used. This work will serve as a baseline to be compared with the results obtained in long-term testing. Furthermore, SEM analysis on some of the best-performing materials for analysing the type of failure, type of deformations and to analyse the microstructure of the specimens will also be tackled in future papers. 


\section{Acknowledgements}

Many thanks to all commercial houses for their contribution to providing all necessary materials to carry out the aforementioned tests and to Ortoplus for its contribution to the study by means of research contract 806/31.4830 with the University of Málaga.

\section{Author contributions}

MGR and JACC involved in conceptualization; MGR, JJCA, JMVG, and JACC contributed to methodology; JJCA and JACC involved in validation; MGR, JJCA, JACC, and ABT involved in formal analysis; MGR, JJCA, JMVG, JACC, and ABT involved in investigation; MGR, JJCA, and JACC contributed to original draft preparation; JJCA, JACC, and ABT involved in review and editing; JACC and ABT contributed to resources. All authors approved the final version of the manuscript.

\section{Funding}

Funding for open access charge: Universidad de Málaga/CBUA.

\section{Declarations}

Conflict of interest The authors declare no conflict of interest.

Open Access This article is licensed under a Creative Commons Attribution 4.0 International License, which permits use, sharing, adaptation, distribution and reproduction in any medium or format, as long as you give appropriate credit to the original author(s) and the source, provide a link to the Creative Commons licence, and indicate if changes were made. The images or other third party material in this article are included in the article's Creative Commons licence, unless indicated otherwise in a credit line to the material. If material is not included in the article's Creative Commons licence and your intended use is not permitted by statutory regulation or exceeds the permitted use, you will need to obtain permission directly from the copyright holder. To view a copy of this licence, visit http://creativecommons.org/licen ses/by/4.0/.

\section{References}

[1] Alghazzawi TF (2016) Advancements in CAD/CAM technology: options for practical implementation. J Prosthodont Res 60:72-84. https://doi.org/10.1016/j.jpor.2016.01.003

[2] Wai R, Chow TW, Pekka J (2016) Ceramic dental biomaterials and CAD/CAM technology: state of the art. J Prosthodont Res 58:208-216. https://doi.org/10.1016/j.jpo r.2014.07.003

[3] Joo H, Park S, Yun K, Lim H (2016) Complete-mouth rehabilitation using a $3 \mathrm{D}$ printing tecnique and the $\mathrm{CAD} /$ CAM double scanning method: a clinical report. J Prosthet Dent 116:3-7. https://doi.org/10.1016/j.prosdent.2016.01. 007

[4] Noort RV (2012) The future of dental devices is digital. Dent Mater 28:3-12. https://doi.org/10.1016/j.dental.2011.10.014

[5] Susic I, Travar M, Susic M (2017) The application of CAD/ CAM technology in dentistry. IOP Conf Ser Mater Sci Eng. https://doi.org/10.1088/1757-899X/200/1/012020

[6.] Mangano F, Gandolfi A, Luongo G, Logozzo S (2017) Intraoral scanners in dentistry: a review of the current literature. BMC Oral Health 17:1-11. https://doi.org/10.1186/ s12903-017-0442-x

[7] Richert R, Goujat A, Venet L et al (2017) Intraoral scanner technologies: a review to make a successful impression. J Healthc Eng. https://doi.org/10.1155/2017/8427595

[8] Granata S, Giberti L, Vigolo P, Stellini E, Di Fiore A (2020) Incorporating a facial scanner into the digital workflow: a dental technique. J Prosthet Dent 123(6):781-785. https://d oi.org/10.1016/j.prosdent.2019.05.021

[9] Di Fiore A, Meneghello R, Graiff L, Savio G, Vigolo P, Monaco C, Stellini E (2019) Full arch digital scanning systems performances for implant-supported fixed dental prostheses: a comparative study of 8 intraoral scanners. J Prosthodont Res 63(4):396-403. https://doi.org/10.1016/j. jpor.2019.04.002

[10] Jacobs R, Salmon B, Codari M, Hassan B, Bornstein MM (2018) Cone beam computed tomography in implant dentistry: recommendations for clinical use. BMC Oral Health 18:1-16. https://doi.org/10.1186/s12903-018-0523-5

[11] Mortadi NA, Eggbeer D, Lewis J, Williams RJ (2012) CAD/ CAM/AM applications in the manufacture of dental appliances. Am J Orthod Dentofac Orthop 142:727-733. https://d oi.org/10.1016/j.ajodo.2012.04.023

[12] Ma B, Park T, Chun I, Yun K (2018) The accuracy of a 3D printing surgical guide determined by $\mathrm{CBCT}$ and model analysis. J Adv Prosthodont 10(4):279-285. https://doi.org/ 10.4047/jap.2018.10.4.279 
[13] Vilarrubi A, Pebe P, Rodriguez A (2011) Prótesis fija convencional libre de metal: tecnología CAD CAM-Zirconia, descripción de un caso clínico. Odontoestomalogia 13:16-28

[14] Bacigalupe RD, Villablanca E (2015) Uso de coronas sistema cad-cam en implantes osteointegrados. Revista Méd Clín Las Condes 25:158-165

[15] Salmi M, Paloheimo K, Tuomi J, Ingman T (2013) A Digital process for additive manufacturing of occlusal splints: a clinical pilot study. J R Soc Interface 10:20130203. https://d oi.org/10.1098/rsif.2013.0203

[16] Kravitz ND, Kusnoto B, Begole E, Obrez A, Agran B (2009) How well does Invisalign work? A prospective clinical study evaluating the efficacy of tooth movement with Invisalign. Am J Orthod Dentofacial Orthop 135:27-35. https://doi.org/ 10.1016/j.ajodo.2007.05.018

[17] Motohashi N, Kuroda T (1999) A 3D computer-aided design system applied to diagnosis and treatment planning in orthodontics and orthognathic surgery. Eur J 21:263-274. https://doi.org/10.1093/ejo/21.3.263

[18] Schweiger J, Edelhoff D, Güth JF (2021) 3D printing in digital prosthetic dentistry: an overview of recent developments in additive manufacturing. J Clin Med 10:2010. h ttps://doi.org/10.3390/jcm10092010

[19] Bozkur Y, Karayel E (2021) 3D printing technology; methods, biomedical applications, future opportunities and trends. J Market Res 14:1430-1450. https://doi.org/10.1016/j.jmrt. 2021.07.050

[20] Haleem A, Javaid M, Hasan Khan R, Suman R (2020) 3D printing applications in bone tissue engineering. J Clin Orthopaed Trauma 1(1):S118-S124. https://doi.org/10.1016/ j.jcot.2019.12.002

[21] Genova T, Roato I, Carossa M, Motta C, Cavagnetto D, Mussano F (2020) Advances on bone substitutes through 3D bioprinting. Int J Mol Sci 21:7012. https://doi.org/10.3390/ ijms21197012

[22] Duarte Campos DF, Philip MA, Gurzing S, Melcher C, Ying Lin Y, Schoneberg J, Blaeser A, Theek B, Fischer H, Betsch M (2019) Synchronized dual bioprinting of bioinks and biomaterial inks as a translational strategy for cartilage tissue engineering. 3D Print Addit Manuf 6(2):63-71

[23] Fernandes MG, Alves JL, Fonseca EMM (2016) Diaphyseal femoral fracture: 3D biomodel and intramedullary nail created by additive manufacturing. Int $\mathrm{J}$ Mater Eng Innov. $\mathrm{h}$ ttps://doi.org/10.1504/IJMATEI.2016.079556

[24] Revilla M, Meyers MJ, Zandinejad A, Ozcan M (2019) A review on chemical composition, mechanical properties, and manufacturing work flow of additively manufactured current polymers for interim dental restorations. J Esthet Restor Dent 31:51-57. https://doi.org/10.1111/jerd.12438
[25] Azari A, Nikzad S (2009) The evolution of rapid prototyping in dentistry: a review. Rapid Prototyp J 15:216-225. https://d oi.org/10.1108/13552540910961946

[26] Horn TJ, Harrysson O (2012) Overview of current additive manufacturing technologies and selected applications. Sci Prog 95:255-282. https://doi.org/10.3184/ $003685012 X 13420984463047$

[27] Gardan J (2016) Additive manufacturing technologies: state of the art and trends. Int J Prod Res 54(10):3118-3132. h ttps://doi.org/10.1080/00207543.2015.1115909

[28] Jiménez M, Romero L, Domínguez IA, Espinosa MM, Domínguez M (2019) Additive manufacturing technologies: an overview about $3 \mathrm{D}$ printing methods and future prospects. Complexity. https://doi.org/10.1155/2019/9656938

[29] Revilla-León M, Özcan M (2019) Additive manufacturing technologies used for processing polymers: current status and potential application in prosthetic dentistry. J Prosthodont 28:146-158. https://doi.org/10.1111/jopr. 12801

[30] Cole D, Bencharit S, Carrico CK, Arias A, Tüfekçi E (2019) Evaluation of fit for 3D-printed retainers compared with thermoform retainers. Am J Orthod Dentofac Orthop 155:592-599. https://doi.org/10.1016/j.ajodo.2018.09.011

[31] Skaik A, Wei XL, Abusamak I, Iddi I (2019) Effects of time and clear aligner removal frequency on the force delivered by different polyethylene terephthalate glycol-modified materials determined with thin-film pressure sensors. Am J Orthod Dentofac Orthop 155:98-107. https://doi.org/10.101 6/j.ajodo.2018.03.017

[32] Iijima M, Kohda N, Kawaguchi K, Muguruma T, Mitsuru O, Naganishi A et al (2015) Effects of temperature changes and stress loading on the mechanical and shape memory properties of thermoplastic materials with different glass transition behaviours and crystal structures. Eur J Orthod 37:665-670. https://doi.org/10.1093/ejo/cjv013

[33] Fang D, Zhang N, Chen H, Ba Y (2017) Dynamic stress relaxation of orthodontic thermoplastic materials in a simulated oral environment. Dent Mater J 32:946-951. https://d oi.org/10.4012/dmj.2013-131

[34] Lombardo L, Martines E, Mazzanti V, Arreghini A, Mollica F (2016) Stress relaxation properties of four orthodontic aligner materials: a 24-h in vitro study. Angle Orthod 87:11-18. https://doi.org/10.2319/113015-813.1

[35] Ledingham AD, English JD, Akyalcin S, Cozad BE, Ontiveros JC, Kasper FK (2016) Accuracy and mechanical properties of orthodontic models printed 3-dimensionally from calcium sulfate before and after various postprinting treatments. Am J Orthod Dentofacial Orthop 150:1056-1062. https://doi.org/10.1016/j.ajodo.2016.04.027 
[36] Favero CS, English JD, Cozad BE, Wirthlin JO, Short MM, Kasper FK (2017) Effect of print layer height and printer type on the accuracy of 3-dimensional printed orthodontic models. Am J Orthod Dentofac Orthop 15:557-565. https://d oi.org/10.1016/j.ajodo.2017.06.012

[37] Kim S, Shin Y, Jung H, Hwang C, Baik H, Cha J (2018) Precision and trueness of dental models manufactured with different 3-dimensional printing techniques. Am J Orthod Dentofacial Orthop 153:144-153. https://doi.org/10.1016/j.a jodo.2017.05.025

[38] Ji SS, Jong-Eun K, Sang HJ, Yeon JC, Jae JR (2020) Printing accuracy, mechanical properties, surfacecharacteristics, and microbial adhesion of 3D-printed resinswith various printing orientations. J Prosthet Dent 124:468-475. h ttps://doi.org/10.1016/j.prosdent.2019.05.034

[39] Alhardi N, Osman R, Wismeijer D (2016) Effects of build direction on the mechanical properties of 3D-printed complete coverage interim dental restorations. J Prosthet Dent 115:760-767. https://doi.org/10.1016/j.prosdent.2015.12. 002

[40] Lin CH, Lin YM, Lai YL, Lee SY (2020) Mechanical properties, accuracy, and cytotoxicity of UV-polymerized 3D printing resins composed of Bis-EMA, UDMA, and TEGDMA. J Prosthet Dent 123:349-354. https://doi.org/10. 1016/j.prosdent.2019.05.002

[41] International Organization for Standardization (2018) Biological evaluation of medical devices-part 1: evaluation and testing within a risk management process (ISO Standard No. 10993-1:2018).

[42] American Society for Testing and Materials (2014) Standard test method for tensile properties of plastics (ASTM D63814).

[43] International Organization for Standardization (2018) Plastics - determination of flexural properties (ISO Standard No. 178:2018).

[44] American Society for Testing and Materials (2017) Standard test methods for flexural properties of unreinforced and reinforced plastics and electrical insulating materials (ASTM D790-17).

Publisher's Note Springer Nature remains neutral with regard to jurisdictional claims in published maps and institutional affiliations. 